\title{
Extração e Funcionalidade de Isolado Proteico do Feijão Fradinho: Propriedades Tecnológicas e Aplicação na Indústria de Alimentos
}

\author{
Caio G. Tullio*, Aurenice M. M. Silva, Flávia S. Almeida, Ana Carla K. Sato
}

\begin{abstract}
Resumo
Este trabalho teve como objetivo estudar dois processos de extração nas propriedades tecnológicas das proteínas do feijão fradinho. Proteínas obtidas por extração alcalina (EA) com pré-tratamento de ultrassom (US) apresentaram maior solubilidade, atividade emulsificante, capacidade de formação de espuma e melhor desdobramento na interface óleo/água. Além disso, as proteínas obtidas por EA com US apresentaram composição centesimal diferente daquelas obtidas somente por EA, apresentando maior pureza. Apesar do US não conferir um aumento significativo no rendimento do processo, este pré-tratamento melhorou as propriedades tecnológicas das proteínas que poderiam ser largamente aplicadas na indústria de alimentos para formação de emulsões e espumas mais estáveis.
\end{abstract}

Palavras-chave: proteína de origem vegetal, emulsão, funcionalidade

\section{Introdução}

As proteínas são muito utilizadas na indústria de alimentos devido as suas propriedades tecnológicas, tais como atividade emulsificante, capacidade em formar gel, além de formação e estabilização de espumas. Atualmente, existe uma tendência no aumento do consumo das proteínas de origem vegetal por conta do aumento de consumidores vegetarianos/veganos e pela demanda de alimentos com baixo teor calórico. Considerando que o feijão fradinho possui alto teor proteico e não há muitos estudos dessa espécie até o momento, optou-se pela utilização dessa matéria prima para a realização do presente trabalho com objetivo de futura aplicação dos concentrados proteicos na indústria de alimentos.

\section{Resultados e Discussão}

Os concentrados proteicos foram obtidos através da extração alcalina seguida de precipitação eletrostática, seguindo a metodologia adaptada de Frota (2008) $)^{1}$. O estudo dos parâmetros dos dois processos de extração (EA, US + EA) revelou que as condições otimizadas para o processo de extração alcalina foram: pH 9,5 para solubilizar as proteínas, $\mathrm{pH} 4,11$ para precipitar as mesmas e 1:20 a razão farinha de feijão:água, sendo que a etapa de desengorduramento não afetou 0 processo. Já a matéria prima que foi submetida ao prétratamento com US (450 W/10 min) apresentou diferenças significativas nos teores de umidade, proteína (menor teor) e extrato etéreo (Tabela 1) quando comparada com a não submetida ao US.

Tabela 1. Composição centesimal dos concentrados proteicos de feijão fradinho

\begin{tabular}{|c|c|c|c|}
\hline $\begin{array}{c}\text { Componentes } \\
(\mathrm{g} / 100 \mathrm{~g})\end{array}$ & $\begin{array}{l}\text { Matéria } \\
\text { Prima }\end{array}$ & Teor (com US) & $\begin{array}{l}\text { Teor (sem } \\
\text { US) }\end{array}$ \\
\hline Umidade & $13,40 \pm 0,08$ & $1,49 \pm 0,17^{a}$ & $2,79 \pm 0,13^{b}$ \\
\hline Proteínas & $33,56 \pm 0,49$ & $73,78 \pm 0,09^{a}$ & $77,15 \pm 0,27^{b}$ \\
\hline Extrato etéreo & $3,22 \pm 0,03$ & $9,37 \pm 0,07^{\mathrm{a}}$ & $6,63 \pm 0,04^{b}$ \\
\hline Cinzas & $2,47 \pm 0,19$ & Traços & Traços \\
\hline $\begin{array}{c}\text { Carboidratos } \\
\text { totais }\end{array}$ & $47,35 \pm 0,79$ & $15,36 \pm 0,33$ & $13,43 \pm 0,44$ \\
\hline
\end{tabular}

Letras minúsculas distintas na mesma coluna indicam que não há diferença estatística pelo teste de Tukey, com 95\% de confiança.

A aplicação do US melhorou a solubilidade das proteínas, proporcionando proteínas com maior funcionalidade, uma vez que estas precisam estar solúveis antes de sua aplicação. A análise dos tamanhos moleculares das proteínas (Fig. 1A) evidenciou que a aplicação do US não alterou o tamanho das frações proteicas. Entretanto, proteínas obtidas por US + EA apresentaram melhores propriedades tecnológicas, tais como: melhor desdobramento da proteína na interface óleo/água (Fig. 1B), maior atividade emulsificante, menor tensão na superfície água/ar (Fig. 1C) e maior capacidade de formação de espuma, demonstrando que o US possivelmente promoveu mudanças estruturais. Além disso, a reduzida solubilidade dessas proteínas em $\mathrm{pH}$ ácido indica que estas poderiam formar um gel ácido mais facilmente se comparadas com as proteínas extraídas sem US.

Fig. 1. Caracterização das proteínas: eletroforese $(A)$, tensão interfacial (B) e tensão superficial (C).

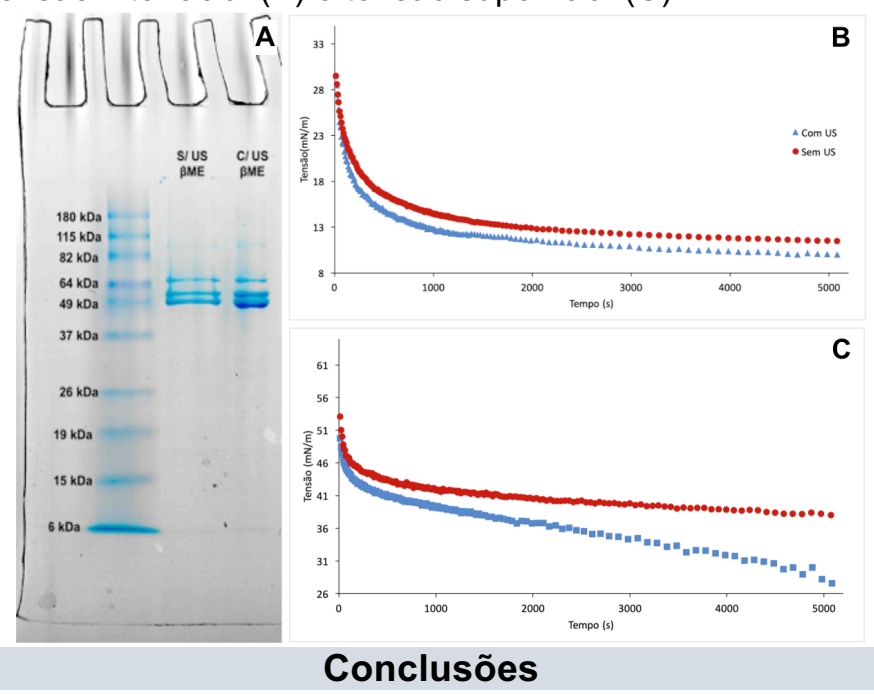

O uso do ultrassom como pré-tratamento não conferiu um aumento significativo no rendimento do processo. No entanto, melhorou as propriedades tecnológicas das proteínas obtidas a partir do feijão fradinho, que poderiam ser largamente aplicadas na indústria de alimentos para formação de emulsões e espumas mais estáveis.

\section{Agradecimentos}

Agradeço ao CNPq pelo apoio financeiro.

${ }^{1}$ Frota, K. De M. G. et al. Composição química do feijão caupi (Vigna unguiculata L. Walp), cultivar BRS-Milênio. Ciencia e Tecnologia de Alimentos, 2008, p. 470-476. 